\title{
Are Medical Students Who Want to Become Surgeons Different? An International Cross-Sectional Study
}

\author{
Sabaretnam Mayilvaganan ${ }^{1}$ Andrew G. Hill ${ }^{2}$
}

Published online: 22 February 2016

(C) Société Internationale de Chirurgie 2016

To the Editor,

We read with interest the article "Are medical students who want to become Surgeons different? An international cross-sectional study" by Baschera et al. [1]. We have a few queries which may be of interest to other readers. Why did the authors not include medical schools from other English medium countries such as India or South Africa? This would have provided a global perspective about surgical interest making the word 'International' more accurate. Further, the response rate was estimated as being $6.4 \%$. Thus, how could the authors draw the conclusions that they have from these data? Finally, what are the actual gender differences in surgical consultants in each of the countries? Is there an increase in female interest in surgery with time?

Thank you for your comments on these issues.

\section{Reference}

1. Baschera D, O'Donnell Taylor E, Masilonyane-Jones T, Isenegger P, Zellweger R (2015) Are medical students who want to become surgeons different? An international cross-sectional study. World J Surg. 39(12):2908-2918. doi:10.1007/s00268-015-3195-1
Sabaretnam Mayilvaganan drretnam@gmail.com

1 Department of Endocrine and Breast Surgery, Sanjay Gandhi Postgraduate Institute of Medical Sciences, Lucknow, India

2 Middlemore Hospital, Counties Manukau Health, University of Auckland, Auckland, New Zealand 